\title{
Erratum to: Italian neuropsychology in the second half of the twentieth century
}

\author{
Giuseppe Vallar · François Boller • \\ Dario Grossi - Guido Gainotti
}

Published online: 5 March 2015

(C) Springer-Verlag Italia 2015

\section{Erratum to: Neurol Sci (2015) 36:361-370 \\ DOI 10.1007/s10072-014-2044-6}

The author would like to correct the following error in the publication of the Review article:

The caption of Fig. 1 text should read as:

Participants in the International Neuropsychological Symposium (INS), that took place in S. Gimignano, Siena, Italy. 1st row from left (1-6) Ennio De Renzi, Brenda
Milner, Martha Wilson, Hans-Lukas Teuber, Henry Hécaen, Carlo Gentili; 2nd row (7-11) Edoardo Bisiach, C. Faust, $\mathrm{M}^{\mathrm{me}}$ I. Gloning, Elizabeth K. Warrington, Marcel Kinsbourne. 3rd row (12-18) Pietro Faglioni, Hans Hoff, F.G. von Stockert, Josephine Semmes, Norman Geschwind, Klaus Poeck, Colwyn Trevarthen. 4th row (19-21) Hans Spinnler, R. Quatember, Luigi A. Vignolo. 5th row (22-25) François Boller, George Ettingler, Sue and John Oxbury"

The online version of the original article can be found under doi:10.1007/s10072-014-2044-6.

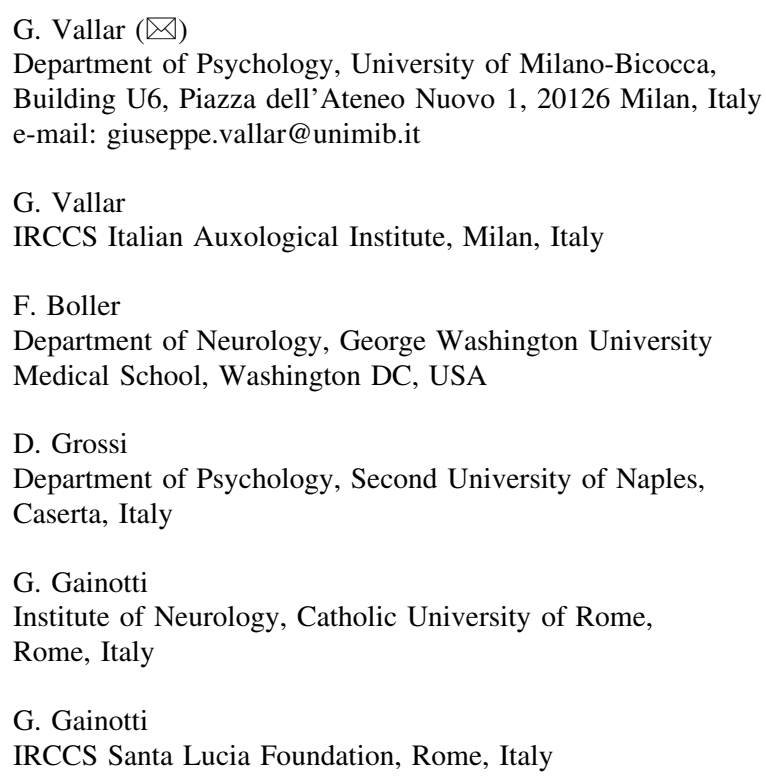

